\title{
ÓLEO DE EUCALIPTO PARA FRANGOS DE CORTE: TITULAÇÃO DE ANTICORPOS EM RESPOSTA À VACINAÇÃO CONTRA BRONQUITE INFECCIOSA E EFEITOS ANTIOXIDANTES
}

\author{
Eucaliptus oil for broiler chicks: Antibody titration in response to infectious bronchitis vaccination \\ and antioxidant effects \\ https://doi.org/10.18593/eba.26262 \\ Recebido em 07 de setembro de 2020 | Aceito em 27 de outubro de 2021

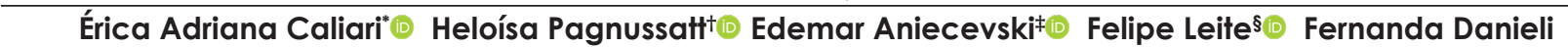

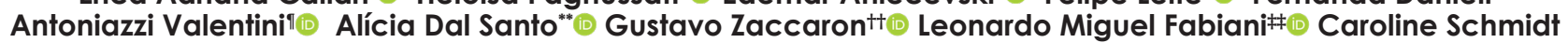

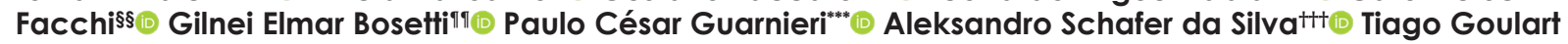
Petrolli\#\#+@
\end{abstract}

Graduanda, Universidade do Oeste de Santa Catarina, Xanxerê, Brasil.

Mestranda do Programa de Mestrado em Sanidade e Produção Animal, Universidade do Oeste de Santa Catarina, Xanxerê, Brasil.

Graduando, Universidade do Oeste de Santa Catarina, Xanxerê, Brasil.

$\S$ Graduando, Universidade do Oeste de Santa Catarina, Xanxerê, Brasil.

" Graduanda, Universidade do Oeste de Santa Catarina, Xanxerê, Brasil.

** Graduanda, Universidade do Oeste de Santa Catarina, Xanxerê, Brasil.

tt Graduando, Universidade do Oeste de Santa Catarina, Xanxerê, Brasil.

抽 Graduando, Universidade do Oeste de Santa Catarina, Xanxerê, Brasil.

§§ Mestranda do Programa de Mestrado em Sanidade e Produção Animal, Universidade do Oeste de Santa Catarina, Xanxerê, Brasil.

กा Mestrando do Programa de Mestrado em Sanidade e Produção Animal, Universidade do Oeste de Santa Catarina, Xanxerê, Brasil.

*** Mestrando do Programa de Mestrado em Sanidade e Produção Animal, Universidade do Oeste de Santa Catarina, Xanxerê, Brasil

tt† Docente da Universidade do Estado de Santa Catarina, Chapecó, Brasil.

łł Doutor em Nutrição e Produção de Monogástricos pela Universidade Estadual Paulista "Julho de Mesquita Filho" Unesp/Jaboticabal; Mestre em Nutrição e Produção de Monogástricos pela Universidade Federal de Viçosa/MG; Professor da Unoesc Xanxerê, Santa Catarina, Brasil.

Resumo: O óleo de eucalipto possui funções antibacterianas, antisséptica, expectorante, e melhoradora de saúde respiratória. Entretanto, estimulam a atividade imune e resposta vacinal, junto aos efeitos antioxidantes destas moléculas, vem sendo alvo de estudos recentes na avicultura, pelo seu potencial. Com isso, objetivou-se avaliar o efeito do óleo de eucalipto sobre a titulação de anticorpos específicos contra Bronquite Infecciosa e sobre parâmetros antioxidantes séricos em frangos de corte (Cobb), do $1^{\circ}$ até $42^{\circ}$ dias de vida dos animais. A pesquisa foi conduzida nas instalações do setor de avicultura da UNOESC Xanxerê, utilizando 8o frangos de corte machos, da linhagem Cobb. Distribuídos no primeiro dia de idade, em delineamento experimental inteiramente casualizado, compostos por quatro tratamentos: Controle, 300 ppm óleo de eucalipto via água de bebida, 300 ppm óleo de eucalipto via nebulização e 300 ppm óleo de eucalipto via água de bebida + 300 ppm de óleo de eucalipto via nebulização, constituídos por 20 repetições, cada ave foi considerada uma unidade experimental. A adição do óleo de eucalipto aumentou a quantidade de anticorpos totais aos 28 dias de idade, no entanto, não propiciou alterações (P>0,05) sobre a titulação 42 dias de idade. Da mesma forma, a capacidade total antioxidante e capacidade de redução do ferro plasmático não sofreram influência $(\mathrm{P}>0,05)$ de acordo com as diferentes adições de óleo de eucalipto nas aves. Conclui-se que óleo de eucalipto, adicionado via água de bebida ou via nebulização, não altera a resposta vacinal contra a Bronquite Infecciosa, bem como não exerce efeito antioxidante no organismo.

Palavras-chave: Avicultura. Cineol. Imunoglobulinas. Líquido.

@ Autor correspondente: Doutor em Nutrição e Produção de Monogástricos pela Universidade Estadual Paulista "Julho de Mesquita Filho" Unesp/Jaboticabal; Mestre em Nutrição e Produção de Monogástricos pela Universidade Federal de Viçosa/MG; Professor da Unoesc Xanxerê; Rua Dirceu Giorani 696, Bairro Jardim Tarumã, 89820-000, Xanxerê, Santa Catarina, Brasil; ORCID: https://orcid.org/0000-0002-6175-5939; tiago. petrolli@unoesc.edu.br. 
Abstract: $\quad$ Eucalyptus oil has antibacterial, antiseptic, expectorant, and respiratory health enhancing functions. However, they stimulate the immune activity and vaccine response, together with the antioxidant effects of these molecules, has been the target of recent studies in poultry, due to its potential. Thus, the objective was to evaluate the effect of eucalyptus oil on the titration of specifications against Infectious Bronchitis and on serum antioxidant parameters in broiler chickens (Cobb), from the 1st to the 42nd day of life of the animals. The research was conducted in the facilities of the poultry sector of UNOESC Xanxerê, using 80 male broiler chickens, of the Cobb lineage. Distributed on the first day of age, in a completely randomized experimental design, consisting of four treatments: Control, 300 ppm eucalyptus oil via drinking water, 300 ppm eucalyptus oil via spray and 300 ppm eucalyptus oil via drinking water + 300 ppm of eucalyptus oil via spray, consisting of 20 replicates, each bird was considered an experimental unit. The addition of eucalyptus oil increased the amount of total totals at 28 days of age, however, it did not provide changes (P>0.05) on the 42-day-old titration. Likewise, the total antioxidant capacity and plasma iron reduction capacity were not influenced ( $P>0.05$ ) according to the different additions of eucalyptus oil in the birds. It is concluded that eucalyptus oil, added via drinking water or via nebulization, does not change the vaccine response against an Infectious Bronchitis, nor does it exert an antioxidant effect on the body.

Keywords: Poultry. Cineol. Immunoglobulins. Liquid.

\section{INTRODUÇÃO}

A Bronquite Infecciosa é uma doença altamente contagiosa, a qual pode ser encontrada em vários ambientes, sendo transmitida por contato direto ou inalação ${ }^{1}$. Entre os sinais clínicos, apresentam complicações no oviduto e nos rins das aves, fazendo com que ocorra uma maior ingestão de água e, consequentemente presença de líquidos nas fezes². A bronquite caracterizase principalmente pelos seus sinais respiratórios, perda de peso e eficiência alimentar reduzida resultando em um impacto econômico muito forte por estarem associadas a enormes perdas econômicas $^{1-4}$.

Os vapores de óleos de eucaliptos possuem propriedades antimicrobianas muito fortes, exercendo forte efeito antibacteriano no epitélio respiratório. Ainda, este óleo atua no sistema imune estimulando a resposta do sistema imunológico, permitindo que os glóbulos brancos do corpo absorvam os nutrientes necessários de que necessitam para lutar contra a doença ${ }^{5}$. A composição do óleo de eucalipto, na forma natural é conhecida como cineol, o qual apresenta atividades farmacológicas (efeitos terapêuticos) em relação a doenças respiratórias como efeitos anti-inflamatório e bronco dilatadores e seu fornecimento via água permite que não ocorram bloqueios nasais devido ao acúmulo de mucos e outras secreções ${ }^{6-8}$.

A funcionalidade dos antioxidantes presentes nestes aditivos, estão relacionadas à compostos que são capazes de proteger o sistema biológico contra os prejuízos gerados por espécies reativas de oxigênio e nitrogênio9. O estresse oxidativo acontece devido a irregular geração de espécies reativas de radicais livres que geram dano de macromoléculas incluindo frações lipídicas e proteicas $^{10}$.

Na avicultura, ocorre a prática rotineira da vacinação em todas as aves, no primeiro dia de vida, de forma a melhorar o controle desta enfermidade nos lotes. No entanto, a efetividade da resposta vacinal é muito variável, e o estudo de alternativas que propiciem comportamento pode propiciar um avanço tecnológico na cadeia produtiva. O funcionamento do sistema imune das aves é baseado em mecanismos como: químicos, físicos, mecânicos, biológicos entre outros ${ }^{11}$. Sendo 
eles: físicas (pele, mucosa, cílios, muco, fluxo de secreções), químicas (Enzimas, pH, peptídeos antibacterianos), biológicas (Microbiota residente - comensal), componente do sistema complemento, células (linfócitos, macrófagos, células dendríticas e neutrófilos), tecidos e órgãos linfoides $^{12}$. O principal ponto em que a imunidade natural está presente é o trato gastrointestinal ${ }^{11}$.

O óleo de eucalipto pode ser utilizado como adjuvante em alguns tratamentos pois inibe o crescimento bacteriano dos microrganismos E. coli e S. aureus ${ }^{13,14}$. Ainda, possui vários outros benefícios como, antisséptico, antibacteriano, desodorante, antiespasmódico, purificador de sangue, diurético, expectorante, antiviral, entre outras $^{12}$. Desta forma, objetivou-se neste trabalho avaliar o efeito da adição de óleo de eucalipto sobre a resposta imunológica (titulação de anticorpos aos 28 e 42 dias de idade) e sobre parâmetros antioxidantes (capacidade total antioxidante e capacidade de redução do ferro plasmático) em aves desafiadas com vacina contra a Bronquite Infecciosa.

\section{MATERIAL E MÉTODOS}

A presente pesquisa foi conduzida nas instalações do setor de avicultura da Unoesc Xanxerê, sendo utilizados 80 frangos de corte machos, da linhagem Cobb, distribuídos no primeiro dia de idade, em delineamento experimental inteiramente casualizado, sendo composto por quatro tratamentos (Tabela 1), constituídos por 20 repetições, sendo cada ave considerada uma unidade experimental. O produto utilizado era composto por óleo essencial da folha de Eucalipto (Eucaliptus spp).
Tabela 1 - Tratamentos utilizados

\begin{tabular}{lll}
\hline Tratamento & \multicolumn{1}{c}{ Aditivo } & \multicolumn{1}{c}{ Dosagem } \\
\hline $\mathrm{T}_{1}$ & Controle & - \\
$\mathrm{T} 2$ & $\begin{array}{l}\text { Óleo de eucalipto via } \\
\text { água de bebida }\end{array}$ & $3 \mathrm{~mL} / \mathrm{L}$ \\
& $\begin{array}{l}\text { Óleo de eucalipto via } \\
\text { spray }\end{array}$ & $3 \mathrm{~mL} / \mathrm{L}$ \\
$\mathrm{T}_{3}$ & $\begin{array}{l}\text { Óleo de eucalipto via } \\
\text { água de bebida }+ \text { spray }\end{array}$ & $3 \mathrm{ml} / \mathrm{L}+3 \mathrm{ml} / \mathrm{L}$ \\
\hline
\end{tabular}

As aves foram alojadas em boxes de 2 $\mathrm{m}^{2}$, sobre cama de maravalha reutilizada, para aumentar o desafio sanitário. O fornecimento via água de bebida ocorreu diariamente, em bebedouros apropriados, desde o primeiro dia de vida das aves. Da mesma forma, a aplicação via nebulização ocorreu diariamente sobre as aves, com nevoa fina sendo aspergida altura das aves, através de nebulizador manual, evitando que a mesma se dissipasse pelo ambiente e atingisse as aves dos outros tratamentos, também sendo efetuada desde o primeiro dia de vida das aves.

As aves foram vacinadas no primeiro dia de vida contra a Bronquite Infecciosa, vacina via spray (Bioral H120, Boehringer-Ingelheim, Paulínia, SP, Brasil), no incubatório. Posteriormente, aos 28 dias de idade, as aves foram submetidas a um desafio vacinal, com a utilização de vacina viva contra a Bronquite Infecciosa, via spray. Previamente a este desafio, foi coletada uma amostra de sangue de cada ave (aos 28 dias de idade) para identificar o perfil sérico prévio ao desafio. Aos 42 dias de idade, foi realizada a segunda coleta, para identificar o efeito da utilização dos aditivos frente ao estímulo imunológico. Não foram realizadas coletas anteriores aos 28 dias de idade devido a influência do perfil de anticorpos das aves ao nascimento (influenciada pelo perfil de anticorpos repassados pela matriz ao ovo) e devido a vacinação normal e 
rotineira que é realizada no primeiro dia de vida das aves.

Para a avaliação da titulação de anticorpos contra a Bronquite Infecciosa, as amostras de sangue foram enviadas ao laboratório Mercolab (Cascavel/PR), para a titulação por meio do método de ELISA. A capacidade antioxidante total (CAT) foi avaliada conforme descrito por Erel ${ }^{15}$ após as adaptações, que são baseadas nas características de branqueamento de um cátion radical mais estável do ácido 2,2'-azino-bis (3-eilbenz-tiazolina-6sulfonico - ABTS) causado por antioxidantes. Pequenas modificações foram feitas na técnica, que se refere a alterações nos tempos de reação (4 min a 5,2 min) e no comprimento de onda no espectofotômetro (6oo $\mathrm{nm}$ a $660 \mathrm{~nm}$ ). A dosagem foi realizada em equipamento de sistema autorizado (BS 380 Mindray ${ }^{\circledR}$, Shenzhen, China). Os níveis da capacidade de redução do ferro plasmático (CRFP) foram medidos de acordo com a técnica descrita automaticamente por Benzie e Strain $^{16}$ que utilizam soro. Os resultados do CRFO foram expressos em $\mu$ mol $\mathrm{L}^{-1}$.

Os dados experimentais foram submetidos a análise de variância, e na ocorrência de efeito significativo, as médias foram comparadas pelo teste Tukey a 0,05 de significância, utilizando o software estatístico R.

\section{RESULTADOS}

Houve aumento na titulação de imunoglobulinas aos 28 dias $(\mathrm{P}=0,043)$ de idade nas aves suplementadas com óleo de eucalipto via água de bebida. Não houveram alterações $(\mathrm{P}>0,05)$ sobre a titulação de imunoglobulinas séricas totais contra Bronquite Infecciosa aos 42 dias de idade (Tabela 2) nos frangos de corte dos diferentes grupos avaliados.

A Tabela 3 apresenta os resultados da capacidade total antioxidante e a capacidade de redução do ferro plasmático de frangos de corte suplementados ou não com óleo de eucalipto, via água ou nebulização, aos 28 e 42 dias de idade. Não foram observadas alterações $(\mathrm{P}>0,05)$ nos níveis de TAC e FRAP de frangos de corte em ambos os períodos de coleta, demonstrando ausência do efeito antioxidante do óleo de eucalipto nas situações testadas.

Tabela 2 - Titulação de anticorpos totais das aves aos 28 e aos 42 dias de idade, submetidas aos diferentes tratamentos

\begin{tabular}{lcc}
\hline \multicolumn{1}{c}{ Tratamento } & \multicolumn{1}{c}{$\begin{array}{c}\text { Titulação de } \\
\text { Imunoglobulinas aos 28 dias }\end{array}$} & $\begin{array}{c}\text { Titulação de Imunoglobulinas } \\
\text { aos 42 dias }\end{array}$ \\
\hline Controle & $369 \mathrm{~b}$ & 636 \\
Óleo de eucalipto via água de bebida & $988 \mathrm{a}$ & 650 \\
Óleo de eucalipto via nebulização & $530 \mathrm{~b}$ & 698 \\
$\begin{array}{l}\text { Óleo de eucalipto via água de bebida + } \\
\text { nebulização }\end{array}$ & $544 \mathrm{~b}$ \\
\hline $\begin{array}{l}\text { CV (\%) } \\
\text { Valor P }\end{array}$ & 19,58 \\
\hline${ }^{*}$ Letras diferentes na mesma coluna indicam diferença significativa pelo teste Tukey ao nível de 5\% de significância & 0,043 \\
\hline
\end{tabular}


Tabela 3 - Capacidade total antioxidante (CAT) e Capacidade de redução do ferro plasmático (CRFP) das aves aos 28 e aos 42 dias de idade, submetidas aos diferentes tratamentos

\begin{tabular}{lccrr}
\hline Tratamento & CAT 28 dias & CAT 42 dias & CRFP 28 dias & CRFP 42 dias \\
\hline Controle & 0,187 & 0,311 & 329,917 & 523,750 \\
Óleo de eucalipto via água de bebida & 0,421 & 0,441 & 366,111 & 321,571 \\
Óleo de eucalipto via nebulização & 0,206 & 0,377 & 393,800 & 536,857 \\
$\begin{array}{l}\text { Óleo de eucalipto via água de bebida + } \\
\text { nebulização }\end{array}$ & 0,188 & 0,347 & 283,182 & 478,714 \\
\hline CV (\%) & 5.46 & 6.79 & 8.49 & 7.57 \\
Valor P & $>0,05$ & $>0,05$ & $>0,05$ & $>0,05$ \\
\hline *Letras diferentes na mesma coluna indicam diferença significativa pelo teste Tukey a o,05 de significância &
\end{tabular}

*Letras diferentes na mesma coluna indicam diferença significativa pelo teste Tukey a o,o5 de significância

\section{DISCUSSÃO}

Aos 28 dias de idade houve influência da utilização do óleo de eucalipto na produção de anticorpos das aves, no entanto, este efeito não se manteve até os 42 dias de criação. Isto demonstra que há um potencial de uso deste produto fitogênico, no entanto, novos estudos devem ser conduzidos a fim de elucidar melhor o seu mecanismo de ação e, principalmente, a forma de utilização do mesmo, para tentar expandir o seu efeito positivo por todo o período de criação das aves.

As variações da aplicação do uso de óleo de eucalipto via água de bebida e seu efeito positivo da aplicação sobre o desempenho da resposta imune é explicado devido ao óleo de eucalipto apresentar propriedades expectorantes e descongestionantes, auxiliando na desobstrução das mucosas, aumento a passagem de ar e facilitando a troca de calor com o ambiente ${ }^{17}$, contudo, o presente trabalho não apresentou efeitos positivos nos quesitos já citados. Frangos possuem maior facilidade em reter calor do que em dissipá-lo, desencadeando assim o estresse térmico e a produção de radicais livres $^{18}$. Ainda, ocorre a inibição da formação de muco nos pulmões, desobstruindo as vias nasais, prevenindo assim a Bronquite Infecciosa ${ }^{19}$.

Considerando que atividade antimicrobiana não seja atribuída a um mecanismo específico, mas sim de atuar sobre vários mecanismos-alvos da célula ${ }^{20}$, os sítios de ação no qual o óleo de eucalipto atua sobre a célula bacteriana são: a degradação da parede celular, danos na membrana citoplasmática e proteínas membranares ${ }^{19}$. Os óleos essenciais exibem sítios de ação antimicrobianos, os quais encontramse, fenóis, cetonas, álcoois e aldeídos são os mais ligados a ação, embora seu mecanismo exato ainda não tenha sido completamente compreendido ${ }^{21}$.

Este óleo apresenta hidrofobicidade, que lhe permite provocar a participação de lipídeos da membrana celular, tornando-as mais permeáveis fazendo com que ocorra o vazamento de íons e dos conteúdos celulares levando assim, a morte da célula bacteriana ${ }^{19}$. Além disso, foram encontrados resultados ${ }^{22}$ com a adição de 150 ppm via água, no período dos 11 aos 42 dias de idade dos frangos, dados como melhoria no desempenho, crescimento, morfologia do íleo, na imunidade (humoral) e na flora microbiana, reforçando assim, 
a ideia de que os óleos de eucalipto são alternativas viáveis na substituição dos antibióticos ${ }^{23}$.

A alteração na expressão de certas enzimas antioxidantes pode determinar o efeito de fatores de estresse como por exemplo, a alta temperatura ${ }^{24}$. As aves tem grande capacidade de produzir anticorpos policlonais, que podem ser direcionados para vários outros antissoros e o óleo essencial pode estimular a produção de imunoglobulinas e elevar a atividade linfocítica ${ }^{25,26}$. As aves possuem imunidades inatas e adaptativas, cuja imunidade inata é a primeira a se desenvolver ${ }^{27}$, sendo composta por células fagocitárias e proteínas, as quais existem mesmo sem a presença de imunógenos.

Alguns trabalhos apontam que os componentes presentes no óleo de eucalipto podem melhorar a resposta imune, através da melhora nos mecanismos celulares e humorais, aumentando a titulação de anticorpos ${ }^{28,29}$. No trabalho de Çarli et al. ${ }^{29}$, os pesquisadores encontraram maior titulação de anticorpos aos 28 dias de idade, estando em acordo com os resultados encontrados na presente pesquisa. Entretanto, tanto os dados da pesquisa citada quanto os dados descritos neste trabalho reforçam que o aumento na titulação de anticorpos é restrito a um período de criação, não sendo eficaz no aumento da resposta imunológica durante todo o período de criação. Atuam ativando os linfócitos T, que fazem o reconhecimento do antígeno e, por meio destes, ligam-se a micro-organismos que estimulam células a produzir citocinas ${ }^{30}$. A imunidade adaptativa são reações a estímulos antigênicos, relacionada aos linfócitos T que maturam no Timo sendo responsáveis pela destruição de antígenos e ativação da resposta imunológica e os linfócitos B que sofrem maturação na Bursa de Fabricius e produzem anticorpos ${ }^{31}$.

Um dos principais contribuintes a taxa de mortalidade é o estresse oxidativo, pois desregula o sistema imunológico levando a doenças, com isso o estresse prejudica a ação anti-oxidativa, pois a peroxidação lipídica aumenta e acumula radicais livres, quando este acúmulo sobreleva a potencialidade anti-oxidativa, acontece a disfunção da célula gerando uma queda no desempenho ${ }^{32,33}$. As plantas aromáticas são ricas em produtos inibidores da oxidação, sendo que seu mecanismo está ligado a fenóis que tem facilidade em doar átomos de hidrogênio aos radicais e assim quebrar a reação de propagação da oxidação ${ }^{34}$. Adicionalmente, alguns trabalhos tem descrito a utilização dos óleos a base de eucalipto graças aos seus mecanismos de ação elencados acima em conjunto com efeitos antimicrobianos ${ }^{35}$, sendo potencial alternativa de utilização na avicultura.

\section{CONCLUSÃO}

Mesmo após o desafio vacinal aos 28 dias de idade, que provoca alto estímulo do sistema imune para a produção de anticorpos específicos para a Bronquite Infecciosa, a adição de óleo de eucalipto via água, spray ou nebulização, não influencia a produção de anticorpos e a capacidade antioxidante do organismo. 


\section{REFERÊNCIAS}

1. Jackwood MW, Wit S. Infectious bronchitis. In: Swayne DE, Boulianne M, Logue CM, McDougald LR, Nair V, Suarez DL, et al., editores. Diseases of poultry. 1st ed. Wiley; 2020. p. 167-88.

2. Matthijs MGR, Ariaans MP, Dwars RM, van Eck JHH, Bouma A, Stegeman A, et al. Course of infection and immune responses in the respiratory tract of IBV infected broilers after superinfection with E. coli. Vet Immunol Immunopathol. 2009;127:77-84.

3. Hassan MSH, Ojkic D, Coffin CS, Cork SC, van der Meer F, Abdul-Careem MF. Delmarva (DMV/1639) infectious bronchitis virus (IBV) variants isolated in eastern canada show evidence of recombination. Viruses. Multidisciplinary Digital Publishing Institute; 2019;11:1054.

4. Tawakol MM, Nabil NM, Samy A. Evaluation of bacteriophage efficacy in reducing the impact of single and mixed infections with Escherichia coli and infectious bronchitis in chickens. Infect Ecol Epidemiol. 2019;9:1686822.

5. Montassier MFS, Brentano L, Montassier HJ, Richtzenhain LJ. Genetic grouping of avian infectious bronchitis virus isolated in Brazil based on RT-PCR/RFLP analysis of the Si gene. Pesq Vet Bras. Colégio Brasileiro de Patologia Animal - CBPA; 2008;28:190-94.

6. Dörsam B, Wu C-F, Efferth T, Kaina B, Fahrer J. The eucalyptus oil ingredient 1,8-cineol induces oxidative DNA damage. Arch Toxicol. 2015;89:797-805.

7. Godoi SN, Fagan SB, Gomes P, Raffin RP, Sagrillo MR, Ourique AF. Biological activities of composite 1,8-cineol associated with nanostrutured systems: a brief review. Disciplinarum Scientia. 2017;18:473-86.

8. Galan DM, Ezeudu NE, Garcia J, Geronimo CA, Berry NM, Malcolm BJ. Eucalyptol (1,8-cineole): an underutilized ally in respiratory disorders? Journal of Essential Oil Research. Taylor \& Francis; 2020;32:103-10.

9. Karadag A, Ozcelik B, Saner S. Review of methods to determine antioxidant capacities. Food Anal Methods. 2009;2:41-60.

10. Falowo AB, Fayemi PO, Muchenje V. Natural antioxidants against lipid-protein oxidative deterioration in meat and meat products: A review. Food Res Int. 2014;64:171-81.

11. Santos TT. Desenvolvimento da mucosa intestinal e imunidade de frangos de corte alimentados com dietas de baixa e alta concentração de fibre e betaína [Tese (Doutorado em Fisiologia)]. Curitiba: UFPR; 2017. 
12. Abbas AK, Lichtman AH, Pober JS. Lymphocyte maturation and expression of antigen receptor genes. Cellular and molecular immunology. 4th ed. Philadelphia, Pa.: Saunders; 2000. p. 125-60.

13. Meireles ASN. Potencialidades terapêuticas de óleos essenciais nas afeções respiratórias. [Dissertação (Mestrado Integrado em Ciências Farmacêuticas)]. Coimbra, Portugal: Universidade de Coimbra; 2019.

14. Cardoso RC, Alcântara AL, Souza FM, Espinheira MJCL. Potencial antimicrobiano do óleo da folha de Eucalyptus urograndis frente stafilococus aureus. ID on line Revista de psicologia. 2019;13:9891002.

15. Erel O. A novel automated direct measurement method for total antioxidant capacity using a new generation, more stable ABTS radical cation. Clin Biochem. 2004;37:277-85.

16. Benzie IF, Strain JJ. The ferric reducing ability of plasma (FRAP) as a measure of "antioxidant power": the FRAP assay. Anal Biochem. 1996;239:70-6.

17. Barbour E, Saade M, Abdel Nour A, Kayali G, Kidess S, Ghannam R, et al. Evaluation of essential oils in the treatment of B roilers co-infected with multiple respiratory etiologic agents. Scopus. 2009 .

18. Lopes J, Ribeiro M, Lima V. Estresse por calor em frangos de corte. Nutritime Revista Eletrônica. 2015;12:4478-87.

19. Burt S. Essential oils: their antibacterial properties and potential applications in foods - a review. Int J Food Microbiol. 2004;94:223-53.

20. Bakkali F, Averbeck S, Averbeck D, Idaomar M. Biological effects of essential oils - a review. Food Chem Toxicol. 2008;46:446-75.

21. Nazzaro F, Fratianni F, De Martino L, Coppola R, De Feo V. Effect of essential oils on pathogenic bacteria. Pharmaceuticals (Basel). 2013;6:1451-74.

22. Hesabi Nameghi A, Edalatian O, Bakhshalinejad R. Effects of a blend of thyme, peppermint and eucalyptus essential oils on growth performance, serum lipid and hepatic enzyme indices, immune response and ileal morphology and microflora in broilers. J Anim Physiol Anim Nutr (Berl). 2019;103:1388-98.

23. Mashayekhi H, Mazhari M, Esmaeilipour O. Eucalyptus leaves powder, antibiotic and probiotic addition to broiler diets: effect on growth performance, immune response, blood components and carcass traits. Animal. 2018;12:2049-55. 
24. Adaszyńska-Skwirzyńska M, Szczerbińska D. Use of essential oils in broiler chicken production - a review. Annals of Animal Science. 2017;17:317-35.

25. Kousted TM, Kalliokoski O, Christensen SK, Winther JR, Hau J. Exploring the antigenic response to multiplexed immunizations in a chicken model of antibody production. Heliyon. 2017;3:e00267.

26. Gopi M. Essential oils as a feed additive in poultry nutrition. Adv Anim Vet Sci. 2014;2.

27. Bastos APA. Imunologia envolvida em aves. Embrapa suínos e aves - artigo em anais de congresso (ALICE). Curitiba: Gessulli; 2015.

28. Awaad M, Afify M, Zoulfekar S, Faten F, Elmenawy M, Hafez H. Modulating effect of peppermint and eucalyptus essential oils on vVND infected chickens. Pakistan Veterinary Journal. 2016;36:35055 .

29. Çarli KT, Önat K, Günaydın E. Application of Mentofin in broilers with clinical infectious bursal disease to reduce Escherichia coli related problems after vaccination against newcastle disease. Turkish Journal of Veterinary \& Animal Sciences. 2008;32:73-8.

30. Robinson MJ, Sancho D, Slack EC, LeibundGut-Landmann S, Reis e Sousa C. Myeloid C-type lectins in innate immunity. Nat Immunol. 2006;7:1258-65.

31. Gertner LRS, Santin E, Saad MB. Influência da fumonisina sobre a resposta imunológica de aves: revisão bibliográfica. Revista Acadêmica Ciência Animal. 2008;6:401-11.

32. Hajian S. Positive effect of antioxidants on immune system. Immunopathol Persa. Nickan Research Institute; 2014;1:e02.

33. Maini S, Rastogi SK, Korde JP, Madan AK, Shukla SK. Evaluation of oxidative stress and its amelioration through certain antioxidants in broilers during summer. J Poult Sci. 2007;44:339-47.

34. Pereira M. Estudo comparativo de métodos de avaliação da capacidade antioxidante de compostos bioactivos [Dissertação (Mestrado em Engenharia Alimentar)]. Lisboa: Universidade Técnica de Lisboa; 2010.

35. Aldoghaim FS, Flematti GR, Hammer KA. Antimicrobial activity of several cineole-rich western australian eucalyptus essential oils. Microorganisms. 2018;6:E122. 
